\title{
Comparison of soil moisture content measurement between Internet of Things (IOT) and traditional methods
}

\author{
Swetha Guduru ${ }^{1 *}$, Dr. Radhika $\mathrm{K}^{2}$, Chandana Sukesh ${ }^{3}$ and Srilakshmi $\mathrm{P}^{4}$ \\ ${ }^{1}$ Assiatant Professor, Dept. of Civil Engineering, Gokaraju Rangaraju Institute of Engineering and Tech., Hyderabad, Telangana. \\ ${ }^{2}$ Professor, Dept. of Civil Engineering, St.Peter's Engineering college, Hyderabad, Telangana. \\ ${ }^{3}$ Assiatant Professor, Dept. of Civil Engineering, Vasireddy Venkatadri Institute of technology, Nambur. Andhra Pradesh. \\ ${ }^{4}$ Assiatant Professor, Dept. of Civil Engineering, RVR \& JC College of Engineering, Guntur, Andhra Pradesh.
}

\begin{abstract}
Soil is a composition of Sand, Silt and Clay. From three phase concept, it is clear that the soil consists of solids, water and air. The ratio of weight of water to weight of solids for a given soil mass is known as water content of soil. In other words, the water content (w) also known as natural water content or natural moisture content. Water content is used in a wide range of scientific and technical areas, and is expressed as a ratio, which can range from zero to the value of the soil porosity at saturation. Traditionally, the water content is measured by pycnometer or oven dry methods which would generally take 24 hours to determine the water content soil. As the time is important these days, several smart advances are occurred in determining the moisture content through Internet of Things (IoT). In this project, the water content of soil is measured through IoT sensors and traditional methods. Present work involves in which different soil samples are taken along the road construction site and classifying them with the help of sieve analysis, Atterberg limits and plasticity chart and moisture content measurement using internet of things (IoT) and traditional methods are compared. Also, find a possible correlation developed between the soil moisture content by traditional methods and through IoT.
\end{abstract}

\section{Introduction}

The water content is identified as the basic property which impacts the behaviour of soils. Moisture content of soil is defined as the ratio of mass of water to the mass of solids present in the soil sample. The measurement of water content provides a basis for soil classification and an indication of engineering properties of mainly clayey soils. It is probably the single most important test carried out in routine geotechnical engineering work and has the advantage of being equally valid on undisturbed and disturbed samples. Many researches have published articles for different soil types for estimating the tentative physical and engineering properties in relation with the water content.

Classical soil moisture measurement involves removing moisture from the soil sample by evaporation by Oven dry methods which would take maximum of 24 hours of time for the whole process Incorrect results can take place where samples are not tested for water content after sampling. The storage of the samples to preserve the water content is very important until the samples are tested in the laboratory. The effort of the traditional process of determining the moisture content will take more time from the sampling in the field and testing in the laboratory. It is more reliable if the moisture content is determined with in few hours after in-situ sampling. As the technology advanced thee days, there are many such ways are readily available in determining the moisture content of the soils. One such method is been more popular is that measuring of moisture content through Internet of Things (IoT). In this work, an effort was made to establish the correlation between the moisture contents determined by the accurate traditional oven dry methods and IoT.

\section{2 loT and Instruments Used}

IoT is Internet Of Things which has two key words, Internet and Things. Internet is a network which acts as a medium through which all our devices are get connected and the Things are any objects with intelligence that are connected to the internet. IoT is a platform where regular devices are connected to the internet so they can interact, collaborate and Exchange data with each other.

The following Instruments used to determine the moisture content using IoT.

\subsection{Arduino Uno R3 Compatible board}

The Arduino Uno R3 Compatible Board shown in figure. 1 is a microcontroller board which is based on the ATmega328. Arduino Uno has 14 digital input or output

\footnotetext{
* Corresponding author: swetha2039reddy@gmail.com
} 
pins (where 6 can be used as PWM outputs), 6 analog inputs, a $16 \mathrm{MHz}$ ceramic resonator, a USB connection, a power jack, an ICSP header, and a reset button.

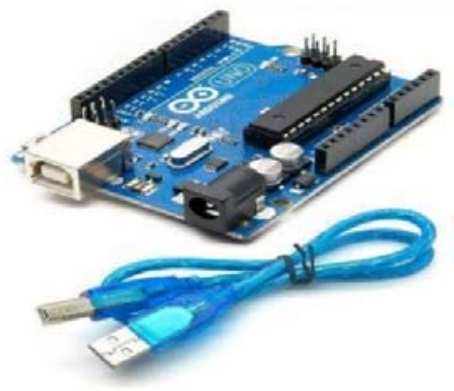

Fig. 1. Arduino Uno R3 Compatible Board.

It has everything needed to support the micro controller, you need to simply connect it to a computer with a USB cable. It is an IDE based on processing, and library functions to easily program the microcontroller. The UNO differed from all preceding boards by featuring the ATmega328P micro controller and an ATmega16U2 programmed as a USB to serial converter.

\subsection{Soil Moisture Sensor}

Soil moisture sensor shown in figure. 2 is used to find the water content of soil with the help of electric conductivity. Soil moisture sensor measures water content indirectly by using other properties of soil i.e, dielectric constant, electrical resistance and interaction of neutrons. It is connected with aurdino board. It uses capacitance to find the moisture content of soil. Rugged sensor is simply inserted into the soil where we want to find water content then after running code in system using Aurdino IDE and when the programme is compiled volumetric water content of soil is reported in percentage.

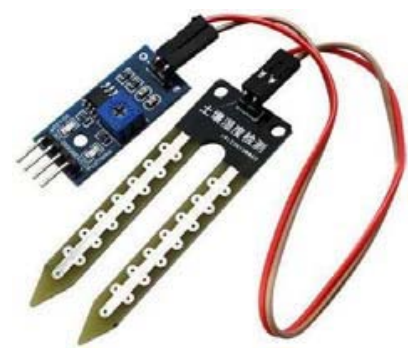

Fig. 2. Soil moisture sensor

\subsection{Jumper wires}

Jumper wires shown in figure. 3 are used to connect the soil moisture sensor to the aurdino board and a usb cable is used to run the programme by connecting system to aurdino board.

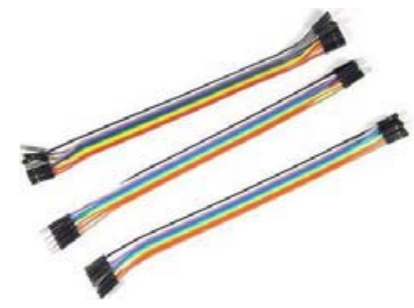

Fig. 3. Jumper Wires.

An Integrated Development Environment (IDE) is software that consolidates as shown in fugure. 4 the basic tools needed for software testing and writing. Without IDE, a developer would have to select and manage all these tools separately, but IDE brings all these tools together as a single framework or service. The soil moisture sensor is connected to aurdino board and the sensor pins into the soil sample which has to be tested. The aurdino board is then connected to system with help of usb cable. The programme of aurdino IDE is uploaded to compile. The Moisture content of soil sample is displayed on system when we click on serial monitor option on right side of guide bar.

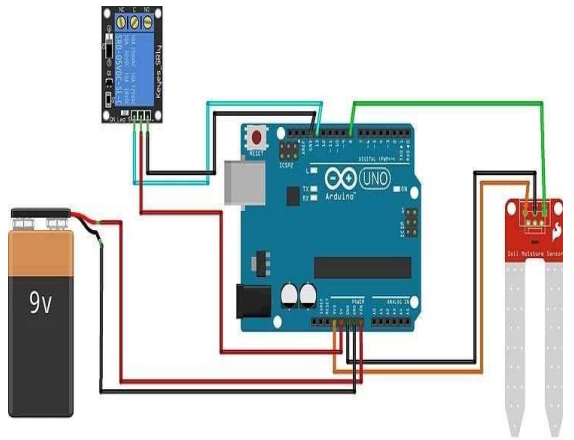

Fig. 4. Circuit Connecting different instruments

\section{Experimental Setup and Results}

The scope includes experimental investigation on water content of different soil samples with IoT soil moisture sensor and compare with Laboratory tests which are done to check the accuracy of results displayed by IoT.

For this study, a total of 120 nos. of different soil samples were considered comprising of both cohesion and cohesionless soils. Cohesive soils are highly compressible clays $(\mathrm{CH})$ and low compressible clays (CL). Cohesionless soil considered are clayey sand (SC) and silty sands (SM). The above said samples are taken along the road construction site. For the collected samples, the basic tests like sieve analysis and hydrometer are conducted to establish the grain size distribution curves. Also, the atterberg limit tests are conducted to establish plasticity characteristics of soil samples. The basis test results of different samples are shown in the table 1 .

Table 1. Basic test results of soil samples

\begin{tabular}{|c|c|c|c|c|}
\hline $\begin{array}{c}\text { Soil } \\
\text { Type }\end{array}$ & $\begin{array}{c}\text { Clay/Sand } \\
\text { Percentage } \\
(\%)\end{array}$ & $\begin{array}{c}\text { Liquid } \\
\text { limit } \\
(\%)\end{array}$ & $\begin{array}{c}\text { Plastic } \\
\text { limit } \\
(\%)\end{array}$ & $\begin{array}{c}\text { Plasticity } \\
\text { Index } \\
(\%) \\
\end{array}$ \\
\hline
\end{tabular}




\begin{tabular}{|c|c|c|c|c|}
\hline $\mathrm{CH}$ & $52-79(\mathrm{C})$ & $50-77$ & $21-34$ & $29-43$ \\
\hline $\mathrm{CL}$ & $54-80(\mathrm{C})$ & $21-35$ & $9-13$ & $12-22$ \\
\hline $\mathrm{SC}$ & $35-46(\mathrm{~S})$ & $23-40$ & $10-20$ & $13-20$ \\
\hline $\mathrm{SM}$ & $11-27(\mathrm{~S})$ & $\mathrm{NP}$ & $\mathrm{NP}$ & $\mathrm{NP}$ \\
\hline
\end{tabular}

NP: Non-Plastic

All the samples collected form the field were properly wrapped to preserve the moisture content. These samples are tested with the IoT instrument and the moisture contents of each sample were recorded to a single decimal number as shown in figure 5 .

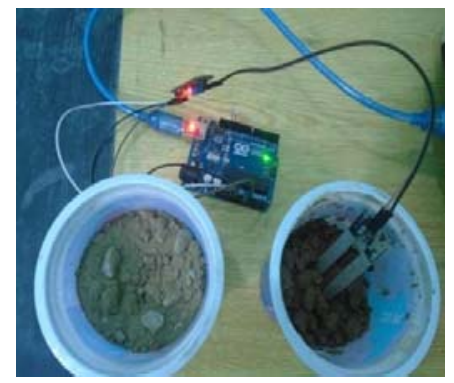

Fig. 5. IoT Moisture Content testing.

Later, to determine the moisture content all the samples tested by IoT are again tested using traditional and accurate oven dry method. The results from traditional methods and from IoT were compared for each type of sample and also, for all types of samples. The graphs are plotted to find the difference of results and a correlation by best fit trend line was established between the traditional method of moisture content and IoT moisture content for each soil type and all soil types.

The graph plotted between the actual water content and IoT moisture content for High compressible clay is shown in figure 6 .

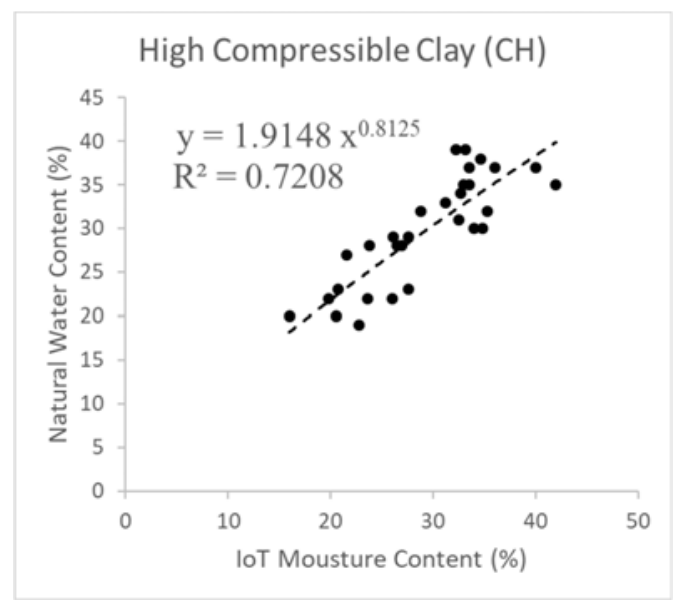

Fig. 6. Natural water content vs IoT Moisture Content for $\mathrm{CH}$.

The graph plotted between the actual water content and IoT moisture content for Low compressible clay is shown in figure 7.
The graph plotted between the actual water content and IoT moisture content for Sandy clay is shown in figure 8 .

The graph plotted between the actual water content and IoT moisture content for silty sand is shown in figure 9 .

The graph plotted between the actual water content and IoT moisture content for all soil types is shown in figure 10 .

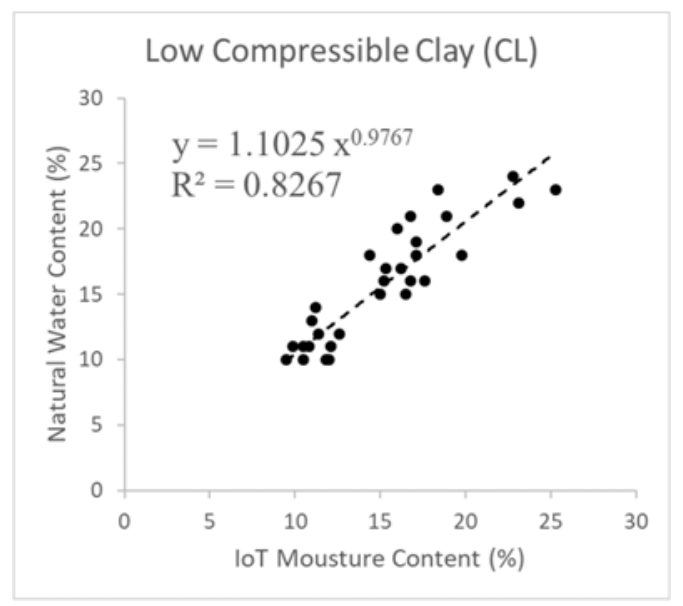

Fig. 7. Natural water content vs IoT Moisture Content for CL

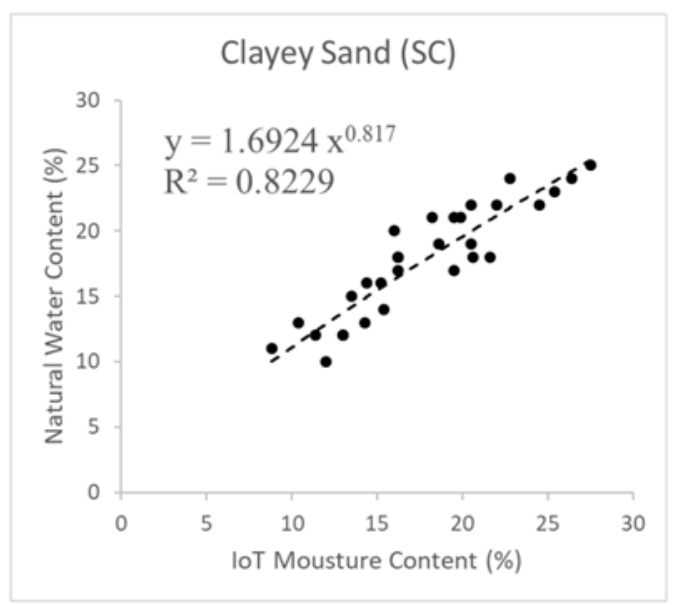

Fig. 8. Natural water content vs IoT Moisture Content for SC 


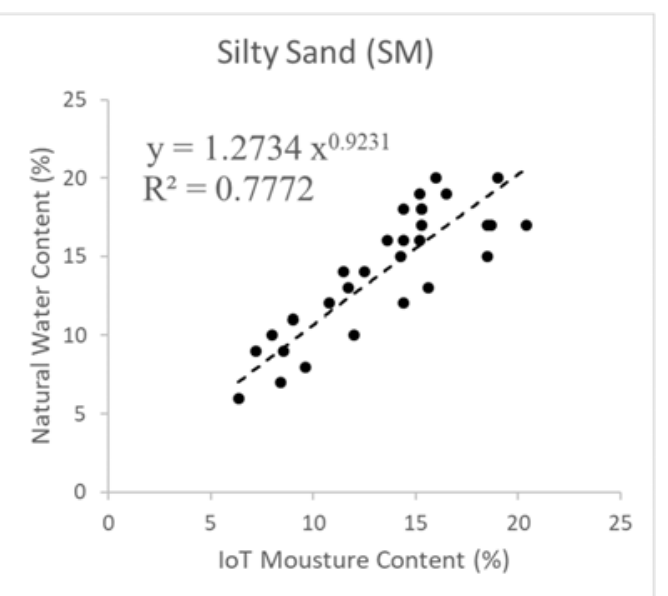

Fig. 9. Natural water content vs IoT Moisture Content for SM

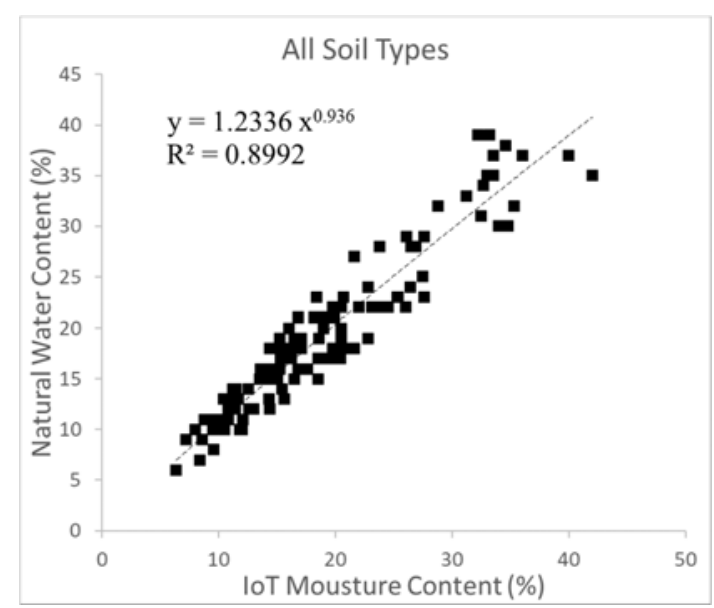

Fig. 10. Natural water content vs IoT Moisture Content for All soil types

\section{Conclusion}

As discussed in the previous sections, the determination of the natural water content will consume more time to compute and also the loss of moisture content would occur in the process of sampling, transporting and conducting test of the soil samples to the laboratory. In order to avoid all these process, it is recommended to take the moisture content reading in the field immediately after sampling.

The co-relations are established based on the above study to calculate the actual moisture content $\left(\mathrm{w}_{\mathrm{n}}\right)$ in the function of IoT moisture content $\left(\mathrm{w}_{\mathrm{IOT}}\right)$. The correlations of the different soil types are shown in below equations.

For High compressible clays $(\mathrm{CH})$, the actual moisture content $\left(\mathrm{w}_{\mathrm{n}}\right)$ is estimated by equation 1 .

$$
w_{n}=1.9148\left(w_{\text {IoT }}\right)^{0.8125}
$$

For Low compressible clays (CL), the actual moisture content $\left(\mathrm{w}_{\mathrm{n}}\right)$ is estimated by equation 2 .

$$
w_{n}=1.1025\left(w_{\text {IoT }}\right)^{0.9767}
$$

For Sandy clays $(\mathrm{SC})$, the actual moisture content $\left(\mathrm{w}_{\mathrm{n}}\right)$ is estimated by equation 3 .

$$
w_{n}=1.6924\left(w_{\text {IoT }}\right)^{0.8170}
$$

For silty Sand (SM), the actual moisture content $\left(\mathrm{w}_{\mathrm{n}}\right)$ is estimated by equation 4 .

$$
w_{n}=1.2734\left(w_{I o T}\right)^{0.9231}
$$

For all soil types, the actual moisture content $\left(\mathrm{w}_{\mathrm{n}}\right)$ is estimated by equation 5 .

$$
w_{n}=1.2336\left(w_{I o T}\right)^{0.9360}
$$

\section{References}

1. Md. Mehzabul Hoque Nahid, Arnob Zahid, Ahmed Abdullah, Rob Ele and Sig Pro Tech (ICREST) 2019 Int Con on, pp. 592-597, 2019.

2. V.D. Bachuwar, U.R. Ghodake, Ahmed Lakhssassi, S.S. Suryavanshi, Smart Systems and Inventive Technology (ICSSIT) 2018 Int Con on, pp. 214-219, 2018.

3. Immanuel Zion Ramdinthara, P Shanthi Bala, Sys Com Auto and Net (ICSCAN) 2019 IEEE Inter Con on, pp. 1-5, 2019.

4. Priyanka Patidar, Sunil Joshi, Int Com and Com Tech (ICCT) 2019 2nd Inter Con on, pp. 157-160, 2019.

5. Ashish Srivastava, Rahul Mahajan, Dnyandeep Sagar, Pratik Shende, Inform and Com Tech (CICT) 2019 IEEE Con on, pp. 1-5, 2019. 